\title{
Vascular Access Complication
}

National Cancer Institute

\section{Source}

National Cancer Institute. Vascular Access Complication. NCI Thesaurus. Code C78709.

Complications related to damage at the vascular access site. Examples include bleeding, formation of hematoma, aneurysm, pseudoaneurysm, or arteriovenous fistula, development of infection, and catheter thrombosis. 